\title{
A HERANÇA COLONIAL E AS IMPLICAÇÕES NA EDUCAÇÃO DO CAMPO NO BRASIL
}

\author{
Adriana do Carmo de Jesus \\ Maria Cristina dos Santos Bezerra \\ UFSCar
}

\section{RESUMO}

Este trabalho discorrerá a respeito da relação campo e educação no Brasil que é historicamente marcada pelo latifúndio e pela violência. Desde a chegada dos europeus, em especial dos portugueses, a organização da produção e a apropriação dos bens da natureza aqui existentes estiveram sob a égide das leis do capitalismo mercantil. Todas as atividades produtivas e extrativistas, desenvolvidas na época, visavam o lucro, que era enviado à metrópole, como forma de realização e de acumulação do capital. Para produzir a maisvalia o europeu provocou o genocídio dos indígenas que aqui viviam e dos negros africanos trazidos forçosamente para as terras brasílicas com o intuito de trabalharem no cultivo de cana-de-açúcar e, posteriormente, do café. No entanto, a violência no campo não é algo específico deste momento histórico. Neste texto encontraremos alguns elementos para a reflexão sobre a herança colonial no campo brasileiro e as implicações nas atuais propostas educacionais.

Palavras chave: Latifúndio, capitalismo e educação do campo

\section{COLONIAL HERITAGE AND IMPLICATIONS IN THE FIELD OF EDUCATION IN BRAZIL}

\section{ABSTRACT}

This paper will talk about the relationship field and education in Brazil which is historically marked by land property and violence. Since the arrival of Europeans, particularly the Portuguese, the organization of production and appropriation of nature's goods were here under the auspices of existing laws of mercantile capitalism. All productive and extractive activities, developed at the time, sought profit, which was sent to the metropolis, as the embodiment and capital accumulation. To produce the added value the EU caused the genocide of indigenous people who lived here and the black Africans brought forcibly to the Brazilian lands in order to work in the cultivation of cane sugar and later coffee. However, rural violence is not something specific to this historical moment. In this paper we find some elements for reflection on the colonial heritage in the Brazilian countryside and the implications for current educational proposals.

Keywords: Land property, capitalism and field education

\section{Introdução}

As pesquisas acadêmicas sobre o campo brasileiro são muito recentes. Segundo Stédile (2011) a carência e a ignorância sobre as questões agrárias em nosso país são frutos da submissão colonial, que impediu o desenvolvimento das ideias, das pesquisas e do pensamento nacional. 
A bibliografia brasileira sobre a questão agrária é muito recente. A rigor, o primeiro grande debate de ideias e teses que interpretavam, de maneira diferente, as origens e as características da posse, da propriedade e do uso da terra no país somente aconteceram na década de 1960 (...) (STÉDILE, 2011, p. 16).

Ainda segundo o autor, antes da década de 1960 apenas alguns estudos foram publicados a respeito da realidade agrária no país; sendo que foi na década de 1970 que se publicaram diversos estudos, construindo-se uma interpretação quase consensual do que havia sido a evolução da posse, da propriedade e do uso da terra, desde o inicio da colonização até os dias atuais.

A partir da interpretação consensual, apontada por Stédile (2011), podemos afirmar que antes da chegada dos portugueses, ao que atualmente conhecemos por Brasil, os 5 milhões de indígenas que aqui viviam se organizavam em um modo de produção que se aproximava ao comunismo primitivo. Unidos por laços de parentescos e isentos do conceito de propriedade; todos os bens da natureza eram de posse e uso coletivo. No entanto, com a invasão dos europeus, em especial dos portugueses, a organização da produção e a apropriação dos bens da natureza aqui existentes estiveram sob a égide das leis do capitalismo mercantil que caracterizava o período histórico já dominante na Europa. Tudo era transformado em mercadoria, inclusive os seres humanos. Todas as atividades produtivas e extrativistas visavam lucro. E tudo era enviado à metrópole européia, como forma de realização e de acumulação do capital (STÉDILE, 2011, p.20).

Os europeus, no Brasil, se organizaram para a produção agrícola de produtos tropicais em larga escala, com a finalidade de abastecer o mercado europeu. Produzia-se para exportar algodão, pimenta-do-reino, cana-de-açúcar, ou extraiam-se plantas nativas como cacau e tabaco. Assim, desde os tempos coloniais o modelo predominante no campo brasileiro foi o agro-exportador. Segundo Stédile (2011)

Tal modelo de produção, sob a égide das leis do capitalismo, produzindo apenas produtos agrícolas e minerais para o abastecimento do mercado europeu, foi denominado pelos historiadores de modelo agroexportador. A amplitude desse modelo era tal que, segundo as primeiras estatísticas macroeconômicas organizadas pelo Banco do Brasil em meados do século XIX, naquela época, a colônia Brasil exportava mais de $80 \%$ de tudo o que era produzido no território (STÉDILE, 2011, p. 20).

Somando-se ao modelo de produção agroexportador, outro traço marcante na produção agrícola brasileira iniciado no período colonial é a permanência da concentração de grandes áreas com a prática da monocultura. Assim, historicamente o avanço do capitalismo no campo tem se nutrido da concentração na propriedade de terras, em um país que já nasceu em bases latifundiárias (STÉDILE, 2011, p. 30).

O desenvolvimento do capitalismo no campo não ocasionou mudanças na estrutura fundiária brasileira, o mesmo não interferiu na distribuição de terra e renda, mas provocaram a expulsão de levas de trabalhadores do campo para a cidade. Na estrutura agrária latifundiária, foi intensificado o investimento do capital, ocorreu a expansão da mecanização agrícola e se deu a subordinação da agricultura à indústria, a partir disto, surgem os grandes complexos agroindustriais. 
Para Alberto Passos Guimarães (2011) no Brasil o monopólio da terra se estabeleceu, e permanece até os dias atuais, em condições pré-capitalistas, ou melhor, a agricultura brasileira mesmo "aburguesada" possui resquícios feudais, e assegura à classe latifundiária um grande poderio econômico, e outra espécie de poder, um poder extraeconômico, que remete ao poder de dominação de uma classe sobre a outra; como o poder do senhor de engenho do período escravocrata, ou do "coronelismo" de antes de 1930. O autor afirma que este tipo de domínio sobre as coisas e pessoas são os vínculos que o latifundismo brasileiro mantém com o feudalismo (GUIMARÃES, 2011, p.53). E, também, que

Graças a esse tipo de relações coercitivas entre os latifundiários e seus "moradores", "agregados", "meeiros", "colonos" "camaradas" e mesmo assalariados, estendendo-se aos vizinhos de pequenos e médios recursos, alguns milhões de trabalhadores brasileiros, vivem, inteiramente ou quase inteiramente, à margem de quaisquer garantias legais ou constitucionais e sujeitos à jurisdição civil ou criminal e ao arbítrio dos senhores de terras. Estes últimos determinam as condições dos contratos de trabalho, as formas de remuneração, os tipos de arrendamento, as lavouras e criações permitidas, os preços dos produtos, os horários de trabalho, os serviços gratuitos a prestar, ditam as sentenças judiciais e impõem as restrições à liberdade que lhes convêm, sem o mínimo respeito às leis vigentes (GUIMARÃES, 2011, p. 51).

E, neste contexto a luta pela reforma agrária adquire um amplo alcance e repercussão, pois segundo o autor em questão o objetivo fundamental de uma reforma agrária democrática é

(...) destruir pela base um duplo sistema espoliativo e opressivo; romper e extirpar, simultaneamente, as relações semicoloniais de dependência ao imperialismo e os vínculos semifeudais de subordinação ao poder extraeconômico, político e "jurídico" da classe latifundiária. E tudo para liberar as forças produtivas e abrir novos caminhos à emancipação econômica e ao progresso de nosso país (GUIMARÃES, 2011, p. 54).

No sentido de endossar a tese de Guimarães (2011) de que os latifundiários exercem poder coercitivo sobre o camponês, destacamos Cassin, Botiglieri e Vale (2011) que ao discorrer a respeito do latifúndio e das determinações violentas do capital na produção agrícola apontam

A composição desigual na ocupação da terra, nas relações de trabalho, na propriedade e na distribuição e comercialização dos produtos, também se manifesta na incorporação de novas tecnologias e nas formas de organização do trabalho. Essa incorporação não se dá de forma homogênea, mas diversificada e, ao mesmo tempo, integrada a determinadas necessidades e interesses. A título de ilustração, citamos as denúncias, ocorridas na Região de Ribeirão Preto/SP, de mortes por exaustão de trabalhadores rurais do corte de cana. Segundo as denúncias, produtores de cana-de-açúcar e usineiros ameaçavam mecanizar o corte da cana se os trabalhadores não cumprissem as metas estabelecidas por ele, o que indica que as novas tecnologias aumentaram a exploração seja pela 
introdução, seja pelo artifício da ameaça de sua implantação (CASSIN, BOTIGLIERI e VALE, 2011, p. 5).

A exploração e violência contra o trabalhador do campo, também, é denunciada por autores como Bernardo Mançano Fernandes (1996) segundo o qual, a luta pela terra no Brasil possui uma longa história e, desde o período colonial - passando pelos quilombos, Arraial de Canudos, as áreas de ocupação do MST e de outros movimentos sociais de luta pela terra - esta tem sido contida através da repressão violenta por parte das classes dominantes, detentora dos meios de produção e do latifúndio.

Desde a chegada do colonizador português, começaram as lutas contra o cativeiro, contra a exploração e conseqüentemente contra o cativeiro da terra, contra a expulsão, que marcam as lutas dos trabalhadores. Das lutas dos povos indígenas, dos escravos e dos trabalhadores livres e, desde o final do século passado, dos imigrantes, desenvolveram-se as lutas camponesas pela terra. Lutas e guerras sem fim contra a expropriação produzida continuamente no desenvolvimento do capitalismo (FERNANDES, 1996, p. 2).

Considerando essas lutas, buscamos contextualizar historicamente os atuais conflitos relacionados ao campo e à educação, e para tal abordaremos, então, de forma sucinta o movimento do campo no século XX e as reivindicações na educação, bem como a atuação de um expressivo movimento social na luta pela reforma agrária e pela educação, a consolidação do paradigma de educação do campo, bem como os principais conflitos e impasses da educação do campo no despontar do novo milênio. Ao passo que este capítulo discorrerá a respeito da luta histórica pela educação do povo que labora na terra, pelos direitos de quem nela trabalha e produz a materialidade humana; relatará uma pequena parte da peleja entre o povo brasileiro e o latifúndio no contexto do século XX. Peleja, esta, que se constitui no aspecto de luta de classes; povo que teve (e ainda tem) seus direitos negados; e latifúndio que tem se firmado através de conflitos e massacres sanguinolentos da classe trabalhadora.

\section{A violência no campo}

Em A situação da classe trabalhadora na Inglaterra, Engels (1975) mostra como o capitalismo atinge violentamente o campo de diferentes formas, como a expulsão do camponês de suas terras; a destruição das relações patriarcais - nas quais os trabalhadores vivem no meio em que trabalham, ou seja, no campo; o assalariamento ${ }^{1}$ e, consequentemente, a baixa dos salários em grandes proporções; este sistema age sempre no sentido de agravar a situação de pobreza dos trabalhadores, de modo que a miséria extrema passa a fazer parte da vida do trabalhador do campo (ENGELS, 1975, p. 323).

$\mathrm{O}$ autor aponta a violência sofrida pelos trabalhadores do campo em países da Europa no século XIX, e as bases da miséria, opressão, coerção física, e das outras formas de violências cujos trabalhadores foram submetidos. Relata que a articulação do trabalhador agrícola em oposição à forma de organização social capitalista foi mais lenta em relação ao trabalhador das minas e da indústria, mas se deu a partir do inverno de 1830 até aproximadamente 1845, com incêndios nos campos de trigo (ENGELS, 1975, p. 327 328).

No Brasil a violência também atingiu os trabalhadores rurais. Os textos de Fernandes (1996) e Stédile (2011) trazem esta afirmativa. Este último ao discorrer sobre o 
trabalho no campo aponta que o modelo agroexportador implementado no Brasil, já na colônia, consistiu em um verdadeiro genocídio.

A população nativa que já habitava o território, em 1500, era de aproximadamente 5 milhões de pessoas. Acrescenta-se que foram trazidos milhões de trabalhadores escravizados da África e, depois de 350 anos de exploração, no fim do século 19, havia pouco mais de 5 milhões de habitantes. Ou seja, foi um grande massacre de nossa população, indígena e negra, pelo capitalista colonizador europeu, que, sem sua presença, teria se multiplicado aos milhões no mesmo período. Além do genocídio que representou a morte de milhões de pessoas escravizadas na África, pelo transporte e pela não adaptação ao território (STÉDILE, 2011, p. 26).

$\mathrm{Na}$ atualidade, os conflitos no campo se fazem presentes e os números ainda assustam, a violência tem-se concretizado no âmbito das organizações dos trabalhadores, no sentido de desarticulá-las. Com efeito, a legislação defensora da propriedade privada e das condições para o lucro e a acumulação do capital tornava, e ainda torna, muitas ações dos movimentos sociais potencialmente ilegais (mas não ilegítimas), permitindo a sua equiparação a condutas delituosas (CALDART, PEREIRA, ALENTEJANO e FRIGOTTO, 2012, p. 675). Verificamos até a tendência de associar os trabalhadores do campo que defendem seus diretos, organizados em movimentos sociais ou não, à criminosos, tornando-se até procurados pela polícia.

Para a Confederação Nacional dos Trabalhadores da Agricultura (CONTAG) a violência no campo no Brasil está diretamente vinculada à concentração da terra e do poder, que a instituição considera como uma das maiores do mundo, sendo que:

menos de 50 mil proprietários rurais possuem áreas superiores a mil hectares e controlam $50 \%$ das terras cadastradas. Cerca de $1 \%$ dos proprietários detém $46 \%$ de todas as terras. Segundo dados do INCRA, existem cerca de 100 milhões de hectares de terras ociosas no Brasil. Ao mesmo tempo, mais de quatro milhões e meio de famílias de trabalhadores e trabalhadoras rurais não possuem terra e vivem num estado de pobreza extrema (CONTAG, 2005, p.1).

Ainda para a entidade, a concentração de terra está diretamente relacionada como a concentração do poder. Os poucos donos das terras, que sempre receberam privilégios e exerceram influência sobre as instâncias do estado brasileiro, além de se sentirem donos da natureza e com isso explorá-la até a exaustão, se comportam como se fossem donos das pessoas, especialmente as mais pobres. Em nome de seus interesses pessoais, financeiros e políticos, os latifundiários exploram, escravizam, ameaçam, torturam e matam aqueles e aquelas que ousam lutar contra seus privilégios. Segundo Informe da Secretaria de Reforma Agrária e Meio Ambiente da CONTAG (2005)

A concentração fundiária brasileira, que tem sua origem na colonização feita pelos Portugueses, foi sendo aprimorada ao longo dos séculos, apoiada pelas políticas governamentais que sempre privilegiaram o latifúndio em detrimento da realização da reforma agrária ou da agricultura familiar. Atualmente, o modelo agrícola embasado no agronegócio monocultor e voltado para a exportação, se expande rapidamente. Fazendeiros, madeireiros, grandes plantadores da soja, de algodão, cana de açúcar, etc., em nome da modernidade e da produtividade, avançam sobre terras públicas, áreas indígenas, áreas 
ocupadas por populações tradicionais e posseiros, ribeirinhos e outros. No afã de ampliar suas terras, acirram os conflitos no campo e produzem a violência das mais variadas formas como a superexploração no trabalho e o trabalho escravo, a grilagem das terras, os crimes ambientais, os espancamentos, seqüestros, ameaças e os assassinatos (CONTAG, 2005, p. 2).

Segundo pesquisa da Comissão Pastoral da Terra (CPT), nos 20 anos da ditadura militar - de 1964 a 1984 -, foram assassinados 42 trabalhadores por ano. De 1985 a 1989, esse número triplicou e chegou a 117 assassinatos por ano. De 1990 a 1993, morreram 52 pessoas na luta pela terra. E, no governo FHC (1994-1997), esse número foi 43 pessoas assassinadas por ano. Número maior que do período da ditadura (MST, 2011).

Em 1995, em Rondônia aconteceu o primeiro grande conflito, na gestão FHC, que resultou na chacina de nove trabalhadores sem-terra e dezenas de feridos e desaparecidos. Naquele ano, 500 famílias haviam ocupado uma fazenda no município de Corumbiara. Por ordem da Justiça, 300 policiais realizaram o despejo das famílias de forma violenta. Aquela ação foi um indicador de que nada mudaria na luta pela terra e a resistência dos povos do campo. Já em 17 de abril de 1996, outro massacre aconteceu no município de Eldorado dos Carajás, no Pará, centenas de famílias sem-terra caminhavam por uma rodovia em direção à cidade de Belém, quando foram surpreendidas pela ação policial. Este caso em especial teve grande repercussão na mídia. A ação violenta da Polícia Militar causou 19 mortes e dezenas de feridos. A caminhada tinha como objetivo pressionar o governo para que as famílias fossem assentadas. Devido ao ocorrido o Movimento dos Trabalhadores Rurais Sem Terra (MST) denominou o dia 17 de abril como o Dia Internacional da Luta Camponesa (MST, 2011).

O MST realizou a Marcha Nacional por Terra, Emprego e Justiça em 1997. Duas mil pessoas partiram de três diferentes pontos do País em direção ao Distrito Federal. A caminhada durou dois meses e na chegada em Brasília, com mais de 30 mil pessoas, tornou-se assunto internacional. Chegaram no dia 17 de abril na capital, lembrando e registrando na memória de toda a sociedade o massacre de Eldorado dos Carajás (MST, 2011).

Bezerra Neto (2009) aponta que apesar das contradições existentes no interior do MST, esse movimento tem assumido e se destacado na tarefa de trazer a tona os conflitos sociais vividos no Brasil, buscando vislumbrar a possibilidade de construção de uma sociedade diferente, uma sociedade que, segundo seus líderes, deve ter como base a solidariedade fraterna entre as pessoas, eliminando-se a relação de exploradores e explorados existente no modo de produção capitalista (BEZERRA NETO, 2009, in: ALVES, 2009, p.7).

Ressaltamos que os conflitos latifundiários e a violência contra o homem do campo estão a séculos presentes na história brasileira, sendo que não reporta somente ao MST. E, é fato que a luta pela terra e pelos direitos dos trabalhadores rurais no interior do estado de São Paulo não se configurou na contramão deste legado. Em relação a isto, Di Pierro e Andrade (2009) apontam inúmeros conflitos ocorridos em São Paulo pela propriedade da terra.

A história da ocupação do território paulista ao longo do século XX foi marcada por frequentes disputas pela propriedade da terra, dentre as quais se sobressaem os conflitos fundiários que, desde os anos de 1960, se desenvolveram no Pontal do Paranapanema, envolvendo posseiros, bóiasfrias e trabalhadores desempregados pela conclusão das obras das grandes 
hidrelétricas da região. O movimento social pela reforma agrária adquiriu nova configuração no início da década de 1980, quando ocorreram ocupações de terras em várias regiões do estado protagonizadas pelo nascente Movimento dos Trabalhadores Rurais Sem Terra, que contou com apoio de setores da Igreja católica. As primeiras ocupações ocorreram na primeira metade da década de 1980, na Fazenda Pirituba, situada nos municípios de Itapeva e Itaberá. Outras ocupações ocorreram em Sumaré, na região de Campinas, onde a interiorização da indústria desencadeou intensa urbanização e atraiu elevado contingente de migrantes de outros estados, boa parte dos quais provenientes do campo, onde haviam sido expropriados da terra (DI PIERRO e ANDRADE, 2009, p. 247).

Com o aumento da intensidade do problema fundiário, surgiram novos movimentos sociais na luta pela terra, como o Movimento dos Atingidos pelas Barragens, a Via Campesina, o MLST, entre outros. Alguns como dissensão do MST, outros formados a partir de suas próprias lutas. O desemprego gera uma demanda crescente, principalmente nas médias e pequenas cidades. Uma opção para os trabalhadores rurais e urbanos é a luta pela terra. Os latifúndios estão em toda a parte, assim como os sem-terra (FERNANDES, 1996).

Ao discutir a atuação dos movimentos sociais de luta pela terra, Antonio Munarim (2008) aponta o relevante papel do MST nas lutas do campo

Nesse contexto, o MST, sem dúvida, pode ser considerado o movimento social de importância vital para o início do Movimento de Educação do Campo. A par de sua permanência, entretanto, convém assinalar que outros sujeitos coletivos forjados em torno da questão do campo, com entrada mais tarde, constituem, hoje, a dinâmica desse Movimento. Destaque-se as organizações de âmbito nacional ou regional, a saber: o Movimento dos Atingidos pelas Barragens (MAB), o Movimento das Mulheres Camponesas (MMC), o Movimento dos Pequenos Agricultores (MPA), sindicatos de trabalhadores rurais e federações estaduais desses sindicados vinculados à Confederação dos Trabalhadores da Agricultura (CONTAG), o Movimento de Mulheres Trabalhadoras Rurais vinculado à CONTAG e que têm sustentado, a campanha chamada "Marcha das Margaridas" -, a Rede de Educação do Semi-Árido Brasileiro (RESAB) e, por fim, a Comissão Pastoral da Terra (CPT), além de uma série de organizações de âmbito local (MUNARIM, 2006, p. 5).

\section{Os movimentos sociais do Campo e a educação: a contribuição do MST}

No campo brasileiro, existem milhares de crianças, jovens e adultos que têm seus direitos fundamentais negados pelo Estado, dentre os quais: terra, trabalho, habitação, saúde e educação. Neste sentido, os movimentos sociais do campo adquiriram maior visibilidade e conquistas no último quarto do século $\mathrm{XX}$ e início do século XXI, articulando lutas com diferentes bandeiras; é o caso, por exemplo, do Movimento dos 
Trabalhadores Rurais Sem-Terra, que na sua luta pela reforma agrária, também luta pela democratização do acesso à educação de qualidade.

Para Vendramini (2007), a educação do trabalhador do campo adquiriu um novo sentido dentro do MST, pois este movimento defende e luta por uma educação articulada com a criação de condições materiais para a vida no campo, consistindo em uma estratégia coletiva de sobrevivência empregada pelos sem-terra, num contexto de vida e de trabalho precário tanto no urbano quanto no rural, esta estratégia revela a capacidade deste movimento de se organizar e criar respostas para as trajetórias de vida e trabalho (VENDRAMINI, 2007, p. 130). Segundo a autora

A defesa de uma educação do campo tem como sustentação o reconhecimento de uma realidade de trabalhadores e trabalhadoras que têm resistido para continuar produzindo sua vida no espaço rural. E, especialmente, o reconhecimento de que esta realidade precisa ser alterada, tendo em vista a crescente pobreza, o desemprego, as grandes desigualdades sociais e as dificuldades de acesso às políticas públicas (saúde, educação, transporte, infra-estrutura etc.) Portanto, pensar um projeto de educação do campo pressupõe a sua sustentabilidade em termos econômicos, sociais e culturais (VENDRAMINI, 2007, p. 129).

O Movimento dos Trabalhadores Rurais Sem-Terra foi fundado em janeiro de 1984, a partir de reivindicações comuns e articulações dos sujeitos do campo, sendo que a primeira sede do movimento se localizava no município de Cascavel - PR, que desde sua origem busca a articulação nacional do movimento. A realização do Primeiro Congresso do MST ocorreu no ano de 1985 em Curitiba (CALDART, PEREIRA, ALENTEJANO e FRIGOTTO, 2012). A considerar que, neste período o Brasil passava por um processo de reconstrução da democracia, e a ocupação das terras foi à forma de resistência e luta encontrada pelos trabalhadores rurais sem-terra para buscar agenda política de forma a viabilizar a conquista da terra e os direitos de quem nela vive e trabalha. Neste ano, o primeiro governo da redemocratização pós-regime militar, também, foi elaborado o I Plano Nacional de Reforma Agrária (PNRA).

O I PNRA foi pensado pela equipe do professor José Gomes da Silva, o plano retratava o ascenso do movimento de massas da época e propunha o assentamento de 1,4 milhão de famílias em quatro anos. Em resposta, os latifundiários se articularam politicamente e de forma armada para combater os movimentos e as lutas sociais. Criaram a União Democrática Ruralista (UDR), que atuou intensamente para que o PNRA jamais fosse implantado (CALDART, PEREIRA, ALENTEJANO e FRIGOTTO, 2012, p. 499).

Segundo Coelho, Lima e Vito (2009), o I PNRA não conseguiu atingir suas próprias metas estipuladas para a implementação da reforma agrária, contexto que desencadeou mais conflitos e ocupações de terras pelo MST já atuante no período.

Nesta perspectiva, entendemos que um fator responsável pelo aumento do contingente na luta pela terra e, por conseguinte pela multiplicação dos sujeitos atuantes em movimentos como o MST é a expansão do capital no campo. No capitalismo o desenvolvimento tecnológico da agricultura contribuiu para ampliação da exploração dos trabalhadores e para o desemprego. Tal qual a realidade analisada por Karl Kaustsky (1968) o capitalismo, ao penetrar no campo, acentua a concentração de riquezas, como também ocorre na indústria, de modo que a opressão dos capitalistas latifundiários sobre a 
classe trabalhadora impede que esta viva com dignidade. E é na luta pela dignidade do homem do campo que as articulações dos movimentos sociais se tecem.

O fato é que os contingentes de lutas, o debate, as ocupações de terra envolvendo os movimentos sociais cresceram expressivamente nos anos de 1990, fortalecendo o MST, que tem se tornado, desde então, o mais organizado e representativo movimento social de luta pela terra (BEZERRA NETO, 1998, p. 257). Concomitantemente, como indica Fernandes (1996), o MST com o apoio da Igreja Católica, dos Sindicatos de Trabalhadores Rurais e de Partidos Políticos, passou reunir famílias para refletirem sobre suas vidas e as perspectivas de trabalho. Formaram diversas organizações locais, analisaram a conjuntura política por meio da construção de conhecimentos sobre a terra e a vida no campo, e tomaram decisões para transformar os seus destinos. Esses trabalhos foram feitos pelos próprios sem-terra, que têm na experiência de vida, a história da luta. Dessa forma, dimensionam os espaços de socialização política e os transformam em espaços de luta e resistência (FERNANDES, 1996, p. 7).

Sendo assim, em momentos de maior permeabilidade do Estado para o atendimento das reivindicações da classe trabalhadora, como na gestão do Governo Lula, algumas das bandeiras do Movimento tornaram-se políticas públicas, muitas destas destinadas à educação, mais especificamente na tentativa de um modelo educacional próprio para o trabalhador do campo.

Deste modo, apreende-se que estes movimentos surgem e se fortalecem, também, com as mudanças nas oportunidades políticas. Entendemos que sua atuação e estratégias de ação estão condicionadas à maior ou menor permeabilidade das suas reivindicações, atuando no sentido de criar agendas públicas. Portanto, é a partir destes pressupostos que tentaremos compreender alguns aspectos históricos do MST relacionados à educação.

Como já sinalizamos acima, para o MST a luta pela terra é concomitantemente à luta pelos direitos dos trabalhadores. Segundo GOBATO (2009)

\begin{abstract}
Entre os direitos encontram-se no centro das lutas pela cidadania, o direito a uma educação que seja pública, gratuita e de qualidade. $\mathrm{O}$ caráter público e gratuito refere-se ao financiamento que deve ser provido pelo poder público, uma vez que é a arrecadação dos impostos dos trabalhadores que abastece os cofres públicos. Já o caráter qualitativo, refere-se a uma educação que seja voltada para o homem e a mulher do campo, especifica para eles e para a realidade e dificuldades que enfrentam, não mais uma educação que seja pensada para a população urbana e impostas aos trabalhadores do campo (GOBATO, 2009, p.16).
\end{abstract}

Para este movimento, faz-se necessário que a educação do trabalhador do campo seja pensada, organizada e desenvolvida no próprio meio rural, de modo que não seja preciso que os alunos se desloquem para bairros urbanos ou cidades mais próximas para estudarem, tendo muitas vezes que percorrerem por horas em transporte escolar e até mesmo realizar grandes caminhadas para chegar ao local do transporte (GOBATO, 2009, p.16). Destacamos ainda que, o transporte escolar por vezes se dá em condições precarizadas, sendo inviabilizados em determinados períodos do ano letivo por conta das chuvas.

Para Andrade e Santos (2009) outro aspecto relevante em relação à proposta de educação do campo desenvolvida pelo MST é a valorização da cultura, apresentada como uma matriz pedagógica, em que o modo de viver, de se relacionar com a terra, e com os outros indivíduos, ocupa papel central no ensino. Nesta perspectiva adota os temas 
geradores como forma de resgatar e valorizar a cultura vivenciada nos assentamentos e acampamentos de Reforma Agrária. Assim, as experiências de exclusão da terra são destacadas, permitindo que a alfabetização comporte a formação política e ideológica dos alunos (ANDRADE e SANTOS, 2009, p. 147).

Nesta perspectiva, podemos inferir que a educação do campo tem sua gênese nas reivindicações dos movimentos sociais, e incorporada às políticas públicas educacionais devido à atuação organizada dos movimentos sociais, bem como, devido às próprias necessidades da sociedade capitalista, cujas relações de trabalho têm-se complexificado e cada vez mais demandado outro perfil de trabalhador, tanto do campo quanto da cidade, a considerar que a escolarização tem papel fundamental na formação dos trabalhadores. De acordo com Cassin, Botiglieri e Vale (2011)

Isto significa organizar a educação para que qualifique a força de trabalho segundo as necessidades do capital, no limite de formação que permita aos trabalhadores operarem as novas máquinas, usarem os novos insumos e defensivos agrícolas, ou, ainda, adaptarem-se à nova organização do trabalho. Para tanto, precisa-se de uma educação que atenda, também, às exigências dos novos postos de trabalho nas atividades agrícolas e que potencialize e diversifique, ainda mais, o consumo dessa população, agora mais hierarquizada segundo os vários setores acima relacionados (CASSIN, BOTIGLIERI e VALE, 2011, p. 54).

Ainda segundo os autores, nas sociedades divididas em classes sociais, o Estado constituiu-se como mediador da relação Trabalho e Educação, organizando ou não, a formação dos trabalhadores com o objetivo de reproduzir as condições de produção, mas sempre organizando as relações de produção de forma a justificar como legítimas a dominação e a exploração pelas classes dominantes (CASSIN, BOTIGLIERI e VALE, 2011, p. 56).

\section{Educação do camponês no contexto das lutas sociais}

Entendemos que a expressão educação do campo refere-se ao processo de escolarização da classe trabalhadora que no campo vive e dele produz a materialidade humana. Trata-se da educação que se volta ao conjunto dos trabalhadores da terra - sejam dos pequenos proprietários aos diversos tipos de assalariados vinculados à vida e ao trabalho no meio rural nos amplos contextos do Brasil contemporâneo, em suas múltiplas contradições, não remetendo apenas a localização geográfica, mas, sobretudo aos contextos econômicos e sociais bastante paradoxais que balizam a sociedade capitalista. Quando tratamos da categoria campo, remetemos a um rural que se relaciona diretamente com as desigualdades socioeconômicas produzidas pela acumulação e concentração de capital. De acordo com Fernandes, Cerioli, Caldart e Frigotto (2004) o termo campo remete à configuração do rural na atualidade. Os autores afirmam que decidiram

utilizar a expressão campo e não mais a usual meio rural, com o objetivo de incluir no processo (...) uma reflexão sobre o sentido atual do trabalho camponês e das lutas sociais e culturais que hoje tentam garantir a sobrevivência deste trabalho (FERNANDES, CERIOLI, CALDART e FRIGOTTO, 2004, p. 25).

Sabe-se que a educação no século XXI, ainda possui dados alarmantes no que concerne ao analfabetismo, como mostram os dados do censo do Instituto Brasileiro de 
Geografia e Estatística (IBGE) que indicam que em 2010 mais de 14 milhões de brasileiros ainda são analfabetos, fato que por si só também caracteriza violência. E, quando se refere especificamente à educação do campo, os índices de analfabetismo são ainda mais preocupantes; haja vista, que há trabalhos de pesquisas, como as de Di Pierro e Andrade (2009) que indicam queda significativa nos últimos dez anos nas matrículas do Ensino Básico nas zonas rurais e a insuficiência de escolas do campo.

\begin{abstract}
As estatísticas educacionais evidenciam o decréscimo no número de escolas e matrículas na zona rural paulista ao longo dos últimos dez anos (...), mas os dados demográficos revelam que um contingente bem mais numeroso de pessoas que vivem na zona rural participa do sistema de ensino, o que demonstra o processo de urbanização da escolarização paulista. Em 2003, por exemplo, enquanto o Censo Escolar do Instituto Nacional de Estudos e Pesquisas Educacionais (INEP) registrava 160.442 estudantes matriculados em escolas na zona rural no estado de São Paulo, a Pesquisa Nacional por Amostra de Domicílio (PNAD) do instituto Brasileiro de Geografia e Estatística (IBGE) contabilizava 590 mil estudantes paulistas vivendo no campo (DI PIERRO E ANDRADE, 2009, p. 246-247).
\end{abstract}

Podemos afirmar que a camada popular, historicamente, não teve acesso garantido à escola pública de qualidade ou padece com uma escolarização precária como aponta os dados oficiais; esta que pouco alfabetiza, pouco prepara para o trabalho e que não objetiva uma formação omnilateral do trabalhador, com acesso aos bens proporcionados pelo poder político e econômico, e que atualmente estão concentrados nas elites (SAVIANI, 2007).

Assim, os dados do IBGE (2009), retirados do sitio do MST na internet, sinalizam a permanência no entre séculos das elevadas taxas de analfabetismo no campo. Os índices de analfabetismo no Brasil no que concerne à população rural, em relação à população urbana, em um período de dez anos mantiveram uma diferença em torno de $20 \%$ o que evidencia a necessidade urgente de discussão e de elaboração de propostas para que a escolarização chegue ao rural (MST, 2011).

No entanto, percebe-se que nas últimas décadas, em especial, muitas das reivindicações dos movimentos sociais tem se concretizado no âmbito das políticas públicas em educação; haja vista que a luta pela educação do campo se tornou uma luta possível devido às próprias mudanças no projeto capitalista para a educação, no qual o analfabetismo na classe trabalhadora se tornou um entrave para o desenvolvimento dos projetos capitalista de produção da base material (BEZERRA NETO e BEZERRA, 2011).

\title{
Considerações finais
}

A história esconde o segredo do presente, esta afirmativa aparece no texto de Octávio Ianni, A ideia do Brasil Moderno (1996, p. 8). E é a partir desta compreensão que recorremos à perspectiva histórica para buscar o entendimento de alguns elementos da atual configuração do rural brasileiro e de sua oferta educacional.

Argumentamos que a herança colonial do Brasil rural se assenta em contextos diversos de violência, que tem se concretizado ao longo da história de diferentes formas e contra o trabalhador rural. Estes contextos vão desde expropriação e expulsão das terras, à negação de direitos, perseguições e assassinatos. 
Dialogando com autores como Stédile (2011) e Fernandes (1996) evidenciamos que os diferentes contextos de violência vivenciados pelos trabalhadores rurais não é algo novo ou recente, típico da contemporaneidade, pois desde os escritos de Engels (1975) sobre os países da Europa, já nos primórdios do sistema capitalista, a violência sofrida pelos trabalhadores rurais tinha bases na miséria, opressão, coerção física, e em outras formas de violências.

Ressaltamos que no Brasil a violência contra o trabalhador rural se concretizou de forma bastante típica, própria de um país que foi colônia de exploração e teve na mão de obra escrava o principal meio de produção da materialidade durante séculos. Assim, podese afirmar que o modelo agroexportador apontado por Stédile (2011) - que teve origem no período colonial - favoreceu, e ainda favorece a concentração de terra e a violência contra o trabalhador.

Retomamos ainda que na contemporaneidade a violência sofrida pelo trabalhador rural brasileiro se configura de modo plural, são frequentes os relatos midiáticos de assassinatos resultantes de conflitos rurais; no entanto, como exposto ao longo do texto há outro contexto de violência que também marcou o rural brasileiro: a escassez de escolas e os altos índices de analfabetismo. Não obstante, verifica-se um relativo esforço neste início do século XXI em buscar a superação destes déficits educacionais por parte dos movimentos sociais que lutam pela terra, que tem conquistado lugar nas pautas das políticas públicas, evidenciando esta situação.

\section{Referências}

ANDRADE, Edinaldo Costa; SANTOS, Fernando Henrique Tisque dos. Viver é lutar: análise do material didático do MEB e do MST para a alfabetização de jovens e adultos. Pós-Graduação da Faculdade de Educação da Universidade de São Paulo, São Paulo: 2009.

BEZERRA NETO, Luiz. Sem-terra Aprende e Ensina: Estudo sobre as práticas educativas do Movimento dos Trabalhadores Rurais. Editora Autores Associados, Campinas: 1999.

; A educação rural no contexto do MST. In: ALVES, Gilberto. Educação no campo: recortes no tempo e no espaço, p. 1-21. Editora Autores Associados, Campinas: 2009

BEZERRA NETO, Luiz; BEZERRA, Maria Cristina dos Santos. Educação do campo: referenciais teóricos em discussão. In: BEZERRA NETO \& BEZERRA (organizadores). Educação para o campo em discussão: reflexões sobre o Programa Escola Ativa. $1^{\text {a }}$ edição: 2011.

; Educação do campo ou educação no campo? Revista HISTEDBR_Online, Campinas, n 38, p. 150-168, junho: 2010.

; A importância do materialismo histórico na formação do educador

do campo. Revista HISTEDBR On-line, Campinas, número especial, p. 251-272, agosto: 2010.

CALDART, Roseli Salete; PEREIRA, Isabel Brasil; ALENTEJANO, Paulo; FRIGOTTO, Gaudêncio. Dicionário de Educação do Campo. Rio de Janeiro, São Paulo: Escola Politécnica de Saúde Joaquim Venâncio, Expressão Popular: 2012.

CASSIN, Marcos; BOTIGLIERI, Monica Fernanda; VALE, Samila. Reestruturação produtiva no campo e as novas exigências de educação, formação e qualificação. In: 
BEZERRA NETO, LUIZ; BEZERRA, Maria Cristina dos Santos. (Orgs.); Educação do campo em discussão: reflexões sobre o Programa Escola Ativa. 2011.

COELHO, Marcos Pereira; LIMA, Aparecida do Carmo; VITO, Rosana Vasconcelos. Politica educacional no campo: espaço de ação dos movimentos sociais populares do campo. Universidade Estadual de Maringá, Paraná: 2009.

COMISSÃO PASTORAL DA TERRA. Conflitos no campo-2011. Disponível em http://www.cptnacional.org.br; acesso em: 07/06/2012.

CONTAG, Confederação Nacional dos Trabalhadores e Trabalhadoras na Agricultura, Informe da Secretaria de Reforma Agrária e Meio Ambiente da CONTAG. A violência e a impunidade no campo. Publicação de 27 de abril de 2005, disponível em: http://www.reluita.org/internacional/ddhh/contag-violencia-campo.htm; acesso em: 18/06/2012.

Di PIERRO, Maria Clara; ANDRADE, Márcia Regina. Escolarização em assentamentos no estado de São Paulo: uma análise da Pesquisa Nacional de Educação na Reforma Agrária 2004. Revista Brasileira de Educação, v.14, n 41, maio/agosto: 2009

ENGELS, Friedrich. A situação da classe trabalhadora na Inglaterra. Tradução: Analia C. Torres. Editora Afrontamento, Porto: 1975.

FERNANDES, Bernardo Mançano. A modernidade no campo e a luta dos Sem Terra. Revista de Cultura Vozes, número 1, ano 90. Editora Vozes, Petrópolis: 1996.

GOBATO, Ana Tatiana Staine Cardoso. As propostas do Movimento dos Trabalhadores Rurais sem terra - MST - para a educação do campo: Há a necessidade de uma formação específica? Trabalho de Conclusão do Curso de Pedagogia. Universidade Federal de São Carlos; São Carlos: 2009.

GUIMARÃES, Alberto Passos. Quatro séculos de latifúndio-1963. in: A questão agrária no Brasil hoje, o debate tradicional- 1500-1960. STEDILE, João Pedro (organizador). Editora Expressão Popular, $2^{\mathrm{a}}$ edição. São Paulo: 2011.

IANNI, Octávio. A ideia do Brasil Moderno, 2 ed. Editora Brasiliense, São Paulo: 1996.

KAUTSKY, Karl. A questão agrária. Tradução de C. Iperoig. Editora Laemmert. Rio de Janeiro: 1968.

MST; site do movimento dos trabalhadores rurais sem terra disponível em: $\underline{\text { ww. mst.org.br }}$ acesso em 20 de julho de 2011.

MUNARIM, Antonio. Movimento nacional de educação do campo: uma trajetória em construção. GT-03: movimentos sociais e educação, disponível em http://www.anped.org.br/reunioes/31ra/1 trabalho/GT03-4244--Int.pdf; 31 $31^{\circ}$ ANPEd: 2008.

SAVIANI, Dermeval. O trabalho como princípio educativo frente às novas tecnologias. In: FERRETI, Celso J. et al (org.). Novas tecnologias, trabalho e educação: um debate multidisciplinar. Editora Vozes, Rio de Janeiro: 1996.

; Aspectos históricos e ontológicos da relação trabalho e educação,

Revista Brasileira de Educação v. 12 n. 34 jan./abr: 2007.

VENDRAMINI, Célia Regina. Educação e trabalho: reflexões em torno dos movimentos sociais do campo. Cadernos CEDES, volume 27, número 72, p. 121-135; Campinas: 2007.

Notas

1 Ao referir-se aos trabalhadores do campo assalariados Engels (1975) utiliza o termo “jornaleiros” que está relacionado com jornadas de trabalho

Recebido em novembro-12

Aprovado em maio-13 